\title{
RETRATOS DO BRASIL: RAÇA E INSTRUÇÃO NOS CENSOS POPULACIONAIS DO SÉCULO XIX
}

\author{
MARIA CRISTINA GOUVÊA* \\ Ana PaUla Xavier ${ }^{* *}$
}

\begin{abstract}
RESUMO: O artigo tem como objetivo analisar a produção dos primeiros censos populacionais nacionais desenvolvidos no Brasil nos anos de 1872, 1890 e 1990. Busca-se apreender a construção de categorias demográficas na homogeneização/segmentação das diferentes populações. Tendo como referência os dados da província/estado do Mato Grosso, tem-se em vista apreender a produção e deslocamento de categorias demográficas, contemplando os dados sobre composição racial e de instrução. Observa-se que as categorias demográficas, mais que organização de dados objetivos, constituem construções sócio-históricas.
\end{abstract}

Palavras-chave: Censos. Categorias demografias. Brasil. Século XIX.

\section{BRAZILIAN PORTRAIT: RACE AND INSTRUCTION IN DEMOGRAPHIC CENSUS OF NINETEEN CENTURY}

ABSTRACT: The aim of this paper is to discuss the production of the first national census of Brazilian population, during the second half of nineteen century $(1872,1890$ and 1990). In order to understand the construction of demographical categories to define and segment the population, we put focus on the data from Mato Grosso province/state. In this sense, we analyze the production and changes on two categories: racial composition and instruction, trying to show that demographic categories, more than an objective data constitutes a social and historical construction

Key words: Census. Demographic categories. Brazil. Nineteen century.

\footnotetext{
* $\quad$ Doutorado em História da Educação e professora associada da Faculdade de Educação da Universidade Federal de Minas Gerais (UFMG). E-mail: crisoares43@yahoo.com.br

** Doutoranda em Educação na Universidade Federal de Minas Gerais (UFMG).

E-mail: anapaulasilvaxavier@hotmail.com
} 


\title{
Portraits DU BRESIL: RACE ET INSTRUCTION DANS LES RECENSEMENTS DE POPULATION DU SIÈCLE XIX
}

\begin{abstract}
RÉSUMÉ: L'article a pour objectif d'analyser la production des premiers recensements de population nationaux mis en oeuvre au Brésil dans les années 1872,1890 et 1990. On y cherche à appréhender la construction des catégories démographiques dans l'homogénéisation/segmentation des différentes populations. En prenant pour référence les données de la province/Etat du Mato Grosso, l'objectif est d'appréhender la production et le changement de catégories démographiques, sur la base des données sur la composition raciale et l'instruction. On observe que les catégories démographiques, plutôt que l'organisation de données objectives, constituent des constructions socio-historiques.
\end{abstract}

Mots-clés: Recensements. Catégories démografiques. Brésil. Siècle XIX.

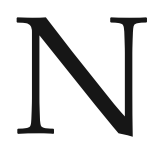

este estudo, buscamos problematizar a produção histórica de censos estatísticos demográficos, entendendo que, mais que conferir visibilidade ao real, através da recolha, categorização e mensuração de dados existentes, a estatística produz representações sobre indivíduos e populações, na construção de agregados.

Para tal, tomamos como objeto de análise os registros do planejamento, execução e resultados dos primeiros censos populacionais nacionais realizados no Brasil, no final do século XIX, contemplando especialmente a composição das categorias "racial" e "instrução". A proposta desta investigação é cotejar os registros de planejamento, execução e resultados dos censos de 1872, 1890 e 1990, na tensão entre a definição de categorias nacionais e as diferentes dinâmicas sociais existentes no país. Sendo assim, optamos por escolher Mato Grosso como espaço analítico, recorrendo às seguintes fontes: documentos que serviram como parâmetros gerais para a construção dos recenseamentos, modelos de boletins que deveriam ser seguidos em todo o território nacional e explicações de como preencher os dados e os documentos de divulgação dos resultados dos recenseamentos de 1872, 1890 e 1900: os chamados recenseamentos gerais.

Buscando situar o desenvolvimento de censos estatísticos nacionais no decorrer do século XIX, apresentaremos a construção histórica da estatística social. Esta tornou possível o levantamento de dados populacionais, fundamentais à produção de condições de governabilidade no período, pelos Estados-nações emergentes. Em seguida, analisaremos como tal saber/técnica foi utilizado na gestão do Estado brasileiro, concentrando-se na apresentação dos resultados de 1872, 1890 e 1900. Por fim, será abordada a aplicação das categorias e classificações censitárias "raça" e "instrução", em Mato Grosso. Nosso foco está centrado na apreensão da lógica operada na elaboração dos agregados que serviram de base para a coleta e o tratamento de 
informações primárias dos censos, bem como na seleção daquilo que compôs a tabela de divulgação dos resultados dos recenseamentos. Desse modo, a intenção não é analisar os dados e as cifras dos censos, mas sim discutir o processo de produção das categorias estatísticas, definidoras de um retrato do país.

\section{A construção da estatística social}

A utilização de técnicas estatísticas como instrumento de contagem desde sempre marcou a administração e gestão pública, ainda que não fundada num saber propriamente científico. No século XVIII, no interior dos processos históricos de cientificização do conhecimento, emerge o vocábulo estatistick, na Alemanha, definido como ciência do Estado. Ou seja, as práticas de governo deveriam ser regidas por saberes e procedimentos referidos a este saber, definindo-se critérios científicos na gestão pública.

Como aponta Martin (2001), é ao longo do século XIX que este ramo científico adquire legitimidade, estendendo seu uso para os mais diversos domínios da vida social. Cabe destacar duas dimensões que iriam conferir à estatística um novo significado naquele período. Por um lado, o recurso ao cálculo das probabilidades permitiu a postulação de uma ciência projetiva, fundamental para a gestão pública; por outro, a construção da chamada estatística social tornou possível o levantamento de dados demográficos.

Tratava-se não mais do uso da estatística apenas como instrumento de contagem, que já era presente em períodos anteriores, mas afirmava-se como prática de governo cientificamente sustentada, voltada para racionalização da gestão pública. Os governos europeus instituíram serviços de estatística na administração estatal. Foram constituídas práticas de registro sistemático dos mais variados aspectos da vida econômica e social, o que Martin (op. cit.) definiu como "febre estatística", fenômeno característico dos oitocentos.

Observa-se um deslocamento do simples registro e contagem, fonte de dados objetivos sobre o presente, para o uso do cálculo das probabilidades, possibilitando a projeção do futuro, indicando cenários sustentados em cálculos numéricos. Neste sentido, o recurso à teoria da probabilidade iria fornecer subsídios para o planejamento administrativo, conferindo condições de previsibilidade, numericamente sustentada. A ciência estatística tornou-se, ao mesmo tempo, "ciência da contagem dos constituintes da sociedade" e "ciência do cálculo em vista da análise das contagens" (MARTIN, op. cit., p. 21). Assim é que a estatística estendeu sua possibilidade de intervenção social, passando da descrição e do diagnóstico, através do registro objetivo dos dados, para a previsão da gestão. A teoria tornou possível, no dizer de Hacking (1990), "conter o acaso", ao viabilizar a construção de categorias de ação e 
intervenção pelo Estado junto aos cidadãos, o que o autor define como uma "tecnologia de poder", característica da modernidade.

Se a teoria das probabilidades forneceu o instrumental técnico que estendeu as possibilidades de utilização da estatística na gestão pública, o referencial teórico para sua aplicação demográfica foi desenvolvido pelo astrônomo belga Quetelet, fundador da chamada estatística social (ou física social, como inicialmente a denominou). Quetelet foi o primeiro cientista a propor a utilização da estatística para avaliação de fenômenos humanos, contemplando grandes populações. O objeto de estudo da física social seria a sociedade, apreendida em sua dimensão quantitativa. Assim seria possível a construção de uma ciência fundada na formulação de leis sociais, dotadas da mesma objetividade das leis da física. No caso do estudo dos fenômenos humanos, para Quetelet, ao contrário da visão universalizante iluminista, os caracteres não seriam invariáveis em suas manifestações, mas sofreriam mudanças de acordo com a época e local. Tais variações corresponderiam às condições históricas e geográficas dadas, determinando diferenciações entre os distintos grupos humanos. Porém, sob as mesmas condições sociais, já que para o autor haveria uma regularidade na vida social, seria possível a previsão de tais manifestações. Em suas palavras: "num certo estágio de desenvolvimento de uma sociedade, a partir da influência de determinadas causas, efeitos regulares são produzidos, que mesmo contendo oscilações, revelam pontos fixos" (QUETELET, 1842, p. 135).

Para o autor, seria possível fazer uma ordenação das nações, a partir da classificação das características morais, intelectuais e físicas de sua população, o que indicaria o grau de seu desenvolvimento civilizatório. $\mathrm{O}$ resultado da medida de todos estes aspectos oferecia uma referência para um "ideal racial", de acordo com o qual as diferentes civilizações seriam comparadas. Em sua visão, uma taxonomia das diferentes populações seria indicativa duma ordem social, análoga à ordem natural, que governaria povos e nações. Knibbis (1910, apud NÓVOA, 2004, p. 9), autor da época, assim definiu o registro estatístico: “a informação mínima necessária para uma administração inteligente do governo [...] os registros sistemáticos substituem as impressões gerais e os destinos das nações passam a ser definidos através dos números".

A constituição de organismos oficiais encarregados de realizar os primeiros censos nacionais - com a criação de órgãos públicos, os serviços de estatística, somados à fundação da Sociedade Estatística Internacional, em 1851 - e a realização das exposições e dos congressos internacionais de Estatística ${ }^{1}$ colaboraram para que a estatística oficial encontrasse no século XIX um terreno fértil na política internacional, conquistando progressivamente sua legitimidade. Nesse período, foi também definida a realização de censos - em latim, census ${ }^{2}$ - decenais pelos distintos países, oferecendo dados que permitissem a avaliação comparativa do seu grau de desenvolvimento. 
Este movimento internacional repercutiu na produção de condições de governabilidade pelo Estado brasileiro, com a institucionalização da realização de censos populacionais decenais desenvolvidos, mesmo que de maneira assistemática, a partir da segunda metade dos oitocentos.

\section{Os recenseamentos do século XIX e a construção da governabilidade brasileira}

No Brasil, os levantamentos censitários existem desde o século XVI, com fins eclesiásticos e, sobretudo, com objetivos militares e fiscais, os quais foram impulsionados pela administração da metrópole portuguesa. ${ }^{3}$ Após a emancipação política brasileira, é possível notar um progressivo empenho por parte do governo em conhecer a situação demográfica e material em que se encontrava o país. Assim, ainda na primeira metade do século XIX, várias províncias brasileiras apresentaram iniciativas quanto à mensuração da população.

As limitações dos levantamentos populacionais brasileiros dos anos de 1830 e 1840 começaram a ser superadas nas décadas seguintes, com a conquista de maior estabilidade pelo Estado monárquico, afirmando cada vez mais a urgência de realização de um censo geral, voltado para obtenção de uma contagem da população em todo o território brasileiro.

Em consonância com essas mudanças, a Lei Orçamentária n. 586, de 1850, autorizou o governo a levar a efeito, no menor prazo possível, o censo geral do Império, assim como a estabelecer registros regulares dos nascimentos e óbitos anuais. Posteriormente, foi fixada a data de 15 de julho de 1852 como referência para realização do censo. Contudo, a notícia da obrigatoriedade do registro civil deu origem a uma série de revoltas armadas pelo Império, impossibilitando levar adiante a realização do censo. Segundo o Visconde de Monte Alegre, ministro do Império, as revoltas foram estimuladas pelo boato de que o registro "só tinha por fim escravizar a gente de cor" (apud BOTELHO, 1998, p. 39). ${ }^{4}$ Percebe-se, neste movimento de resistência, a expressão - segundo Mattos (2009) - de processos de luta antidiscriminatória presentes naquele período que, ao mesmo tempo que aceitavam a escravidão, rejeitavam atos discriminatórios contra a população negra livre.

Se, por um lado, a experiência do censo de 1852 mostrou-se frustrada, por outro serviu para trazer definitivamente ao âmbito do Ministério do Império a competência para organizar a estatística da população, por meio de diversos instrumentos estatais criados a partir de então. ${ }^{5}$

A iniciativa mais concreta para a realização do primeiro recenseamento nacional brasileiro deu-se por meio da Lei n. 1.829, de 1870, que no seu artigo ${ }^{2}{ }^{\circ}$ previa 
a criação da Diretoria Geral de Estatística (DGE) na capital do Império, tendo por atribuição coordenar os levantamentos estatísticos no país e realizar os censos populacionais. No ano de 1871 o Decreto n. $4.856^{6}$ definiu os conceitos, as instruções de execução do censo e a data para a realização do mesmo.

De acordo com Botelho (1998, p. 178), o censo de 1872 significou que: “[...] o medir da nação estaria articulado não mais com os interesses metropolitanos, mas com temas como a implantação das políticas públicas (fim da escravidão, por exemplo), a questão eleitoral e o próprio reconhecimento do rosto que assumiria o povo brasileiro"

O Recenseamento Geral do Império de 1872 foi, ao mesmo tempo, o primeiro levantamento populacional brasileiro realizado em âmbito nacional, o último operacionalizado no regime monárquico e o único ainda sob a vigência da escravidão. O trabalho censitário contou com as associações litúrgicas dos párocos ${ }^{7}$ (ainda que temporária) na execução de várias tarefas que normalmente deveriam estar sob o encargo de funcionários do Estado. Contudo, as limitações técnicas da época fizeram com que a publicação do Censo só fosse possível no ano de $1877^{8}$ (DIRETORIA GERAL DE ESTATÍSTICA, Relatório, 1877, p. 7).

Após a finalização do primeiro censo, a Diretoria deixou de ser provida de condições mínimas de funcionamento, sendo desativada em 1879 pela Lei n. 2.940. Isso tornou inviável a realização do censo de 1880, interrompendo o fluxo dos censos decenais, como previsto. Apesar de inúmeras tentativas de retomada efetiva dos trabalhos desenvolvidos pela DGE, a reabertura da repartição só veio a lume em 1890.

Logo após a Proclamação da República, a DGE foi restaurada pelo Decreto n. 113, de 1890 e, em seguida, deu-se início às atividades relativas ao novo levantamento da população.

O censo 1890 realizou-se, praticamente, nas mesmas bases de 1872 , no tocante à definição de família e de domicílio especial, bem como à estrutura organizacional, cronograma e penalidades legais. Isso não significa dizer que não houve diferença entre um e outro. Segundo Botelho (1998, p. 60-61), no censo de 1890 "as mudanças mais sensíveis ocorreram na parte de execução do censo". Embora a paróquia continuasse a ser a área geográfica mínima de referência, a laicização repentina do Estado, promovida pela Proclamação da República, fez com que as comissões censitárias fossem preferencialmente presididas pelo subdelegado do distrito, sendo também compostas por mais três membros indicados pelos presidentes das mesmas. Esse quadro, no qual as comissões assumiriam a face de "funcionário público", fez com que predominasse a desconfiança e até mesmo a resistência da população em relação aos trabalhos dos recenseadores. Assim é que o processo de 
recenseamento de 1890 também foi demorado e as publicações foram parceladas, sendo concluídas em $1898^{\circ}$ (SYNOPSE, 1890).

Os anos de 1890 a 1900, segundo Machado (2008), foram marcados pela reduzida produção de estatísticas e pela supressão de cargos na DGE. Isso fez com que o terceiro recenseamento do país fosse instituído em 20 de janeiro de 1900. Os resultados foram divulgados sob a forma de resumo, em 1905, sob nome de Synopse do recenseamento de 1900, já indicando os problemas enfrentados na sua totalização.

\section{As categorias estatísticas: deslocamentos no registro da composição racial}

Ao investigarmos o processo de construção dos recenseamentos realizados no final do século XIX e seus dados finais, destacamos os registros de "raça" e "instrução", problematizando-os no estudo de sua aplicação num contexto regional específico: o estado de Mato Grosso.

Ao contemplarmos a categoria raça, verifica-se que esta foi historicamente ponto de tensão na construção dos censos populacionais. Diversos recenseamentos regionais realizados na primeira metade do século apresentavam o critério "raça"10 com uma enorme variação nas classificações, já outros preferiam não incluir tal dado na estatística. Carvalho (2004, p. 1) aponta que, em 1849, Haddock Lobo, organizador do censo do Rio de Janeiro, rejeitou o item "cor" por considerar essa classificação odiosa, além de inconfiável pela "infidelidade com que cada indivíduo faria de si próprio a necessária declaração".

O Recenseamento Geral de 1872 - primeiro e único censo de abrangência nacional do período imperial e escravista - enfrentou o problema da classificação da cor e utilizou o termo raça, sendo definidos os seguintes registros: branca, preta, parda e cabocla (Decreto n. 4.856, de 1871). A classificação de raça/cor preta foi utilizada para designar pessoas africanas, negras e crioulas. A denominação "parda" caracterizava o cruzamento da raça africana com outras raças. Já a designação cabocla deveria ser compreendida como raça indígena ou, ainda, como a mistura entre brancos e indígenas. ${ }^{11}$

Cabe considerar que, segundo a condição social - definição jurídica -, os indivíduos foram classificados em "livres" e "escravos". Em análise sobre o tema, Oliveira (2003, p. 14) observa que:

Era a partir da questão da escravidão que a sociedade brasileira se interrogava sobre suas possibilidades de coesão, seus riscos de fratura e seus rumos no futuro. E era a 
partir da separação entre homens livres e escravos que o perfil daquela sociedade recebia seus contornos mais nítidos e se projetava.

Nos quadros de resultado do recenseamento consta um número significativo dos segmentos da população preta, parda e cabocla constituído de pessoas na condição de livres. ${ }^{12}$ Já os homens e as mulheres na condição de escravos - não possuidores do status de cidadão - só receberam a designação de pretos ou pardos. Assim é que fatos como a mudança jurídica, mobilidade e status social ou mudanças na percepção de cor que o chefe do domicílio ou o recenseador tinham acerca dos membros do fogo ${ }^{13}$ poderiam alterar a classificação dos indivíduos.

As extensas pesquisas sobre a história das relações raciais no Brasil indicam que o termo raça não foi historicamente associado à "carga hereditária" e/ou à cor da pele, mas a outras características como a posição social e o lugar que os indivíduos ocuparam nas relações sociais. ${ }^{14}$ Do mesmo modo, as classificações da categoria "raça" fixadas nos censos podem ser compreendidas muito mais como categoria social do que "cor" da pele. Considerando que o censo de 1872 desenvolveu-se no interior de um Estado escravista, em que o critério racial era superposto pela condição jurídica, no censo de 1890, no contexto de uma república recém- instituída, constituída por homens livres, independente de sua identidade racial, a questão racial foi ressignificada.

No desenrolar da realização do censo de 1890, o modelo de Boletim Individual ${ }^{15}$ repete o padrão do censo anterior, apresentando o campo "cor". Contudo, não consta nenhuma observação sobre a raça. Conforme as explicações de como preencher os quesitos, nesse campo deveria ser indicado se o individuo tinha a cor branca, preta, cabocla ou mestiça. Segundo as disposições do Decreto n. 659, de 1890, essas designações de cor - sem conceituação - deveriam ser preenchidas no campo "raça". E, assim, o documento de resultado final do censo de 1890 seguiu as referências de cor expressas nas explicações dos boletins.

Os responsáveis pelo censo de 1890 substituíram o termo "pardo" por "mestiço", argumentando que

Como ficou provado pelo recenseamento de 1872, um preconceito social muito conhecido frustra a exata averiguação do fato étnico resultante da fusão do elemento africano; resta, portanto, englobá-lo ao que provém da origem cabocla, embora mais conveniente fosse a discriminação, no interesse da ciência. (p. 42 apud OLIVEIRA, 2003, p. 14)

Contudo, cabe salientar que o critério "raça" foi abandonado nos censos de 1900 e 1920, com alegação de que as respostas, em especial a classificação de mestiço, ocultavam a variedade étnico-racial da população. Tal tensão contribuiu para que o registro da cor só fosse reintroduzido no censo nacional de 1940. Assim, a inclusão, 
exclusão e o deslocamento de categorias estatísticas levam-nos a pensar na ambiguidade que acompanha o significado de determinadas classificações. ${ }^{16}$

Em Mato Grosso, considerando a significativa presença de negros e indígenas, a composição étnico-racial traz uma complexificação das relações sociais, nem sempre expressa nas categorias estatísticas. Se a análise da classificação racial dos censos vem sendo largamente abordada em relação à população negra, cabe avaliar como a população indígena foi contemplada.

Nos levantamentos populacionais realizados em Mato Grosso, nos séculos XVIII ${ }^{17}$ e XIX, ${ }^{18}$ é possível encontrar indígenas e seus descendentes sendo classificados com diversos termos como "índio", "mestiço", "caboré", entre outros. Contudo, a população indígena computada se restringe a já aldeada, ou razoavelmente integrada à sociedade da época.

De acordo com Botelho (1998), Mato Grosso e Goiás eram províncias caracterizadas pela pequena participação de brancos e presença significativa de indígenas. Por um lado, o alto número de indivíduos pardos e caboclos apresentados no censo de 1872, assim como o número de caboclos e mestiços do recenseamento de 1890 indicam a intensa miscigenação racial de Mato Grosso. ${ }^{19}$ Por outro, tais dados devem necessariamente ser problematizados, dadas as questões apontadas.

As classificações de raça experimentaram deslocamentos semânticos ao longo da história, fruto das alterações nas relações raciais. Nos mapas de população de Mato Grosso no século XVIII, o termo "mestiço" aparece acompanhando a população indígena, na classificação "índio e mestiço" e a palavra "pardo" ao lado da população negra, com as seguintes denominações: "pardos e pretos forros" e "pardos e pretos cativos".

No século XIX, em Mato Grosso, os levantamentos populacionais classificaram os indígenas como "índios" e "caboclos". ${ }^{20}$ Esta última denominação foi usada na estatística demográfica, tanto para designar os indígenas, em geral, como para expressar a miscigenação de brancos e índios (PESOVENTO, 2004). Já a designação de "pardo", servia para referendar a miscigenação entre diversos segmentos étnicos (SIQUEIRA, 2000).

Embora na documentação do censo de 1872 estivesse prevista a identificação das diversas tribos indígenas e suas línguas, na versão final, contudo, prevaleceu a orientação de se englobar indistintamente os indígenas sob a categoria caboclos. Para Oliveira (2003, p. 15):

É possível que o foco sobre a questão do escravo e, consequentemente, do negro eclipsasse a questão indígena. Mas é possível também que a indiferenciação das tribos se acomodasse ao intuito de conferir maior homogeneidade à população brasileira, evitando que esta se apresentasse dividida em tribos, com línguas e costumes diversos. 
Se considerarmos que a definição do pardo apresentada nas instruções do censo de 1872 caracterizava-se pela mistura da raça africana com outras raças, é possível pensarmos nas mais variadas combinações raciais em Mato Grosso, pois, conforme Mattos (1995, p. 104), desde o período colonial brasileiro, a designação de pardo foi usada "como forma de registrar uma diferenciação, variável conforme o caso, na condição mais geral de não branco". Já o termo "mestiço" - inexistente nas instruções de 1872 e não conceituado no processo de 1890 - também era aplicado a filho de preto com branco ou, ainda, a indivíduos de uma raça que se cruza com outra (LELLO;LELLO, s.d.).

Ao contrapor os registros nacionais e regionais do processo de elaboração do recenseamento de 1872 e 1890, é possível perceber um deslocamento dos termos "pardo", "mestiço" e "caboclo". As instruções do censo de 1872 indicam as cores branca, preta, parda e cabocla. Já os registros da coleta de dados do ano de 1872, realizada nas duas freguesias urbanas de Cuiabá, capital de Mato Grosso, apresentam o termo "mestiço" em detrimento do "pardo". ${ }^{21}$ Em contra partida, o documento de resultado final, publicado pela DGE, substitui a referência "mestiço" por "pardo", mantendo assim a organização estabelecida nas instruções nacionais. No interior do processo censitário de 1890, a migração dos termos indica maior complexidade das relações étnico-raciais.

No censo da população urbana de Cuiabá, datado de 1890, constam apenas três raças: branca, preta e parda. Desse modo, os recenseadores locais registraram grande parte da população como "parda", suprimindo ou agrupando as referências "cabocla" e "mestiça", indicadas pelas explicações expedidas pela Diretoria em 1890. Essa absorção nos leva a pensar que tanto os descendentes de negros como indígenas e, ainda, os ditos mestiços foram classificados como pardos. Ao sistematizar as informações enviadas pelo Serviço de Recenseamento de Mato Grosso para proceder com a totalização dos dados nacionais, a DGE substituiu a referência de pardo, reclassificando os indivíduos em caboclo e mestiço, mantendo ainda as referências "branca" e "preta". Dessa forma, por mais que o recenseamento propusesse uma uniformização nacional, as terminologias de classificação racial empregadas nos dados estatísticos da população não agregavam, necessariamente, o mesmo significado nas diversas localidades brasileiras.

O caso de Mato Grosso, dada a composição racial de sua população, com forte presença indígena, introduz um importante elemento na discussão sobre a categorização da composição racial brasileira nos censos. A miscigenação gerou uma imensa gama de designações, ${ }^{22}$ como, por exemplo, mulato, cafuzo, caboclo, mameluco, pardos, entre outros, que não se adequam perfeitamente a nenhum esquema de categorias de cor ou raça. Sendo assim, as categorias estatísticas precisam ser consideradas a partir de uma interpretação que leve em conta as relações sociais, em 
especial, entre os que aferem e são classificados com tais terminologias, assim como as intencionalidades destes registros e a condição social dos indivíduos que recebem estas designações. Mas o que dizer da exclusão do critério raça no censo de 1900? É interessante analisar a justificativa utilizada para o abandono da categoria raça:

Explica-se pelo fato de que as respostas ocultaram em grande parte a verdade, especialmente com relação aos mestiços, muito numerosos em todos os Estados do Brasil e de ordem os mais refratários a cor a que pertencem [...] sendo que os próprios indivíduos nem sempre podem declarar sua ascendência, considerando que o cruzamento ocorreu na época da escravidão ou em estado de degradação moral da progenitora do mestiço. Além de essa tonalidade de pele deixar a desejar como critério discriminatório, por ser elemento incerto. (apud LAMOUNIER, s./d.)

Pode-se inferir que a forte presença das teorias raciais no Brasil no período, que tomavam o negro como raça inferior e o mestiço - entre ele, o índio - como degenerado, produziu efeitos na construção/abandono de categorias do censo de 1900, eliminando a categoria racial e apagando um dos importantes traços na construção de um retrato do país.

Por outro, ao mesmo tempo em que apagou o registro da composição racial brasileira, o censo de 1900 fez exaustivo e minucioso levantamento do número e procedência dos imigrantes e da nacionalidade de todos os indivíduos que contraíram matrimônio no período, bem como a filiação paterna e materna. Observa-se que o registro dos matrimônios de brasileiros com estrangeiros (discriminando cada nacionalidade), item ausente nos censos anteriores, bem como a filiação, demonstra a importância da nacionalização desta população e homogeneização do brasileiro. Nas orientações, esta questão assim se expressava: "[Ela] servirá para evidenciar o grau de homogeneidade com que se formou a população nacional em um certo período, e ao mesmo tempo demonstrará o coeficiente de assimilação do fator estrangeiro pelo mais poderoso dos laços - o das afeições domésticas" (apud OLIVEIRA, 2003, p. 15).

Desse modo, as estatísticas dos recenseamentos expressam posições e interesses que estão imbuídos na maneira como são organizados os dados, nas categorias estabelecidas, assim como na decisão do que incluir ou excluir nos documentos de divulgação dos censos. Longe de serem neutras e imparciais, as estatísticas são produzidas buscando conformar maneiras de perceber o mundo social, conferindo-lhe inteligibilidade.

\section{Dados sobre instrução: distinção entre alfabetização e escolarização}

Ao longo do século XIX, os discursos de governantes e intelectuais brasileiros enfatizavam que, para que o país pudesse figurar ao lado das "nações mais civilizadas", era preciso proporcionar instrução elementar para toda população. 
Na documentação que indica o processo de construção da categoria "instrução" observa-se também deslocamentos e ambiguidades, num percurso nada linear ou progressivo, na sua produção, ligado a uma política de Estado.

No censo de 1872, a questão educacional, inicialmente, apresenta-se em dois campos de registro do modelo da "lista de família": campo "instrução", subdividido em "sabe ler" e "saber escrever" e o campo "condições especiais e observações", no qual deveria constar, entre outras coisas, informações a respeito das crianças de 6 a 15 anos que frequentavam a escola, ${ }^{23}$ uma vez que essa faixa etária era prevista pelas distintas leis de obrigatoriedade escolar das províncias. Tais itens deveriam ser assinalados com "sim" ou "não". No documento de resultado final, estes registros foram organizados em dois gráficos, nos quais os aspectos referentes à instrução, especialmente a frequência escolar para as crianças, apontam elementos de distinção social.

O quadro geral da população livre, além de indicar o número de homens e mulheres que sabiam "ler e escrever" num campo e os "analfabetos" em outro, também registrou a população escolar e aquela não presente na escola. Em contrapartida, o quadro geral da população escrava apresentou apenas os subcampos "saber ler e escrever" e "analfabetos", ${ }^{24}$ pois os escravos eram impedidos, legalmente, de frequentar a escola (embora se fizessem presentes no espaço escolar). ${ }^{25}$

Ao ser incluído no censo de 1872, o registro da frequência escolar colaborava para a construção da própria ideia do que fosse a escola. No caso, cabe chamar a atenção sobre como o censo, mais que registrar a frequência escolar, buscava dar visibilidade à instituição, projetando-a como espaço de inserção da população de pessoas livres entre 6 e 15 anos, independente da raça. No caso de Mato Grosso, foram contabilizados, em 1872, 7.114 homens livres que indicavam saber ler e escrever, 20.877 analfabetos, enquanto foram registradas 3.808 mulheres que sabiam ler e escrever e 21.951 analfabetas. Os dados sobre a província são coerentes com os estudos acerca das diferenças históricas no acesso ao letramento, tendo em vista o pertencimento de gênero. No que se refere à frequência à escola, foram registrados 881 meninos que a frequentavam e 5.401 que não o faziam, bem como 338 meninas que frequentavam a escola e 6.187 que não estavam na instituição. ${ }^{26}$ Assim, por um lado, a quantificação dos que frequentavam a escola buscava indicar a concretização dos esforços do governo em ampliar a oferta da escolarização, como também assinalar a necessidade de afirmação da escola como espaço privilegiado de formação das novas gerações, uma vez que a instituição escolar disputava com outros espaços educacionais, como família, trabalho, Igreja, entre outros. Por outro lado, o enorme descompasso entre a população alfabetizada e a que frequentava a escola demonstra como a instituição estava longe de se constituir como espaço legitimado de acesso à cultura escrita. 
No censo de 1890, a instrução também foi apresentada em dois campos de registro do modelo de boletim que trazia informações do indivíduo em relação à sociedade: o campo "saber ler e escrever" deveria ser respondido com "sim" ou "não", se o indivíduo fosse ou não completamente analfabeto; e o campo "título científico, literário ou artístico" deveria ser preenchido caso o indivíduo possuísse título ou diploma, para designar se era "de médico, legista, engenheiro, clérigo, professor e de que matéria, etc.". Estas indicações da lógica de construção e levantamento de dados sobre o nível de educação da população foram complementadas pelo Decreto n. 659, ao afirmar que o item "habilidade intelectual" deveria indicar se o indivíduo sabia "ler e escrever" e também se o habitante tinha instrução secundária ou superior, se possuía título ou diploma científico, literário ou artístico.

Nos registros de levantamento de dados das duas freguesias urbanas de Cuiabá, em 1890, a categoria "instrução" foi subdividida em dois campos: "saber ler" e "frequenta a escola", tendo como opção de resposta "sim" ou "não". Apesar de relacionados, esses campos não eram equivalentes, pois quem sabia ler e/ou escrever não frequentava, necessariamente, a escola e vice-versa. A organização dessas classificações nos leva a pensar que a estatística dos recenseamentos procurou representar diferentes dimensões da escolarização ${ }^{27} \mathrm{e}$ do acesso à cultura escrita.

O registro de frequência indica o esforço de legitimação da instituição escolar, sem a qual não parecia plausível o intuito de reverter a péssima situação educacional do país. Dessa forma, apesar da ausência física da escola prevalecer em Mato Grosso, a indicação do número da frequência era uma das formas encontradas para the conferir legitimidade.

No que se refere às condições de letramento (alfabetização), o documento de registro de informações, localizado em Mato Grosso, excluiu a designação "escrever", mantendo apenas o item "sabe ler". A supressão desse termo dá-nos margem para problematizarmos os significados sócio-históricos do conceito de alfabetização. Analisando os processos históricos de aprendizado da escrita, verifica-se que este envolvia o domínio de habilidades complexas e o acesso a materiais caros, condições do uso da pena na execução de uma sofisticada caligrafia. Assim, não apenas no Brasil, historicamente, os dados sobre leitura e escrita eram diferenciados, com a leitura sendo mais difundida que a escrita (VIÑAO FRAGO, 1992).

No caso de Mato Grosso, o estudo de Xavier (2007) aponta que, até o final do século XIX, o ler e o escrever constituíam-se habilidades distintas na instrução pública mato-grossense e que o aprendizado da leitura antecedia o da escrita. ${ }^{28}$ Ao dar a ver a contabilização do alcance do ensino da leitura, independente do fato de o habitante ter ou não frequentado a escola, ou mesmo se a estava ou não frequentando, a organização dos dados do levantamento realizado na Capital, em 1890, 
buscava retratar as diferentes possibilidades de acesso à cultura escrita, no contexto de uma sociedade em que a escola não tinha a legitimidade social suficiente para afirmar-se como espaço privilegiado de instrução. Assim, a contabilidade do número de indivíduos que já sabiam ler, em Mato Grosso, possivelmente, incluiu tanto os indivíduos que, mesmo não permanecendo no processo de escolarização, adquiriram os rudimentos da leitura, como os que vivenciaram outros espaços e estratégias de instrução.

Já no documento de divulgação nacional do censo de 1890, o quadro da população recenseada introduz o termo "analfabetismo" em seu título. ${ }^{29}$ No interior do quadro, o item "frequência escolar" foi suprimido. Nas orientações, tal supressão foi assim justificada:

\footnotetext{
Não se propõe o recenseamento a levantar uma estatística escolar. Na coluna em que indaga se o recenseado sabe ler e escrever, será incluído o menor que tiver esse grau de instrução não só em colégio, como no seio da família, método de ensino muito razoavelmente seguido em várias casas. Se na coluna profissão, na linha correspondente ao menor inscrever-se: estudante escolar, completa ficará a informação que se pretende obter. (apud OLIVEIRA, 2003, p. 17)
}

Como observa Oliveira, a exclusão deste dado antecipa, de certa forma, a exclusão promulgada na Constituição do ano seguinte da obrigatoriedade escolar, garantida pelo Estado.

Os dados educacionais foram dispostos em dois grandes campos: o campo "sabe ler e escrever", separado por sexo e especificando se brasileiro ou estrangeiro. Já o campo "não sabe ler e nem escrever" englobou tanto brasileiros como estrangeiros, especificando apenas o número de pessoas por sexo. Nesse período, a população do estado de Mato Grosso somava 92.827 habitantes, sendo 15.175 brasileiros que sabiam ler (10.443 homens e 4.732 mulheres), 504 estrangeiros que sabiam ler (378 homens e 126 mulheres). Os mato-grossenses e estrangeiros que não sabiam ler e nem escrever totalizavam 77.148, sendo 36.375 homens e 40.773 mulheres. ${ }^{30}$

Nos registros educacionais do censo de 1900 há um maior deslocamento para a questão do analfabetismo. No modelo do boletim individual, a categoria instrução apresenta apenas o item "sabe ler e escrever". Já na Sinopse do censo de 1900, referente à instrução - que pode ser encontrada no relatório da DGE no ano de 1908 -, há ênfase na descrição dos analfabetos. O quadro "sexo, nacionalidade e analfabetismo dos habitantes" apresenta os campos "analfabetos brasileiros", "analfabetos estrangeiros" e "analfabetos de nacionalidade ignorada", sendo subdivididos por sexo e por idade (menores e maiores de 15), sem nenhuma menção ao número de alfabetizados e/ou dos que frequentavam a escola. De acordo com esse gráfico, em 1900, havia em Mato Grosso 86.214 analfabetos, sendo 40.149 homens e 46.065 mulheres. Dos habitantes 
analfabetos, 40.890 foram registrados como menores de 15 anos, sendo 20.709 homens e 20.181 mulheres. Já os 45.278 analfabetos maiores de 15 anos eram 19.407 homens e 25.871 mulheres (DIRETORIA GERAL DE ESTATÍSTICA, Relatório, 1908).

Como aponta Ferraro (2002), o analfabetismo no Brasil não assumia um caráter pejorativo e desqualificante ao longo do século XIX, com uma população marcadamente iletrada. Com a mudança da lei eleitoral de 1881, que excluiu o voto dos analfabetos, o indivíduo que não dominava o código escrito foi sendo, progressivamente, representado como não cidadão (em termos políticos). Por outro lado, a capacidade da escrita assumiu maior valor, na medida em que viabilizava o exercício do voto. Neste sentido, mais que uma questão econômica ou cultural, a alfabetização tinha um sentido político.

Nesse processo de produção da categoria "instrução" dos censos do final do século XIX é possível observar que os sucessivos deslocamentos na construção das categorias de registro refletem a complexa composição educacional brasileira do período, com um amplo leque de possibilidades de acesso/exclusão e interação com a cultura letrada. Assim é que o estudo desses recenseamentos possibilita dar visibilidade a uma multiplicidade de configurações de instrução e níveis de letramento, contemplando desde o indivíduo analfabeto, que não teve acesso à escola, passando por aquele que apenas dominava a leitura, sem que tal aprendizagem tivesse ocorrido na instituição, até o diminuto universo dos que alcançaram níveis superiores de escolarização.

\section{Conclusão}

A análise dos censos demográficos do século XIX permite-nos explorar uma importante dimensão na produção de um retrato da nação e sua população. Como buscamos demonstrar, tal retrato, mais que um registro do real, consistia na projeção de uma representação da população, lançando luz sobre alguns aspectos, ao mesmo tempo em que deixando outros opacos, nas sombras, ou invisíveis.

É importante que a história da educação explore com maior sistematicidade esta importante fonte. Ela nos oferece uma base empírica para melhor apreender a trajetória da educação brasileira e seus sujeitos, no entrecruzamento com outras fontes. Mas não se pode desconsiderar que os dados estatísticos tanto fazem falar como calar o real, ao submetê-lo ao registro numérico. Cabe ter em vista seu caráter de produção discursiva, tendo como signos não a letra, mas o número. Sem ignorar a importância e riqueza do recurso à estatística, como bem nos ensinou Foucault (1984), cabe-nos apreendê-la no interior da ordem do discurso, para melhor significá-la. 


\section{Notas}

1. Segundo Gil (2007, p. 58), desde 1851, quando realizada a Exposição de Londres, as exposições e congressos internacionais foram considerados "instâncias privilegiadas dos padrões assumidos como adequados para a civilização ocidental".

2. Census, em latim, significa "conjunto dos dados estatísticos dos habitantes de uma cidade, província, estado, nação etc.".

3. Sobre levantamentos populacionais do século XVI a XVIII, no Brasil, ver Nadalin (2004) e Marcílio (1977).

4. A expressão "gente de cor" caracterizava pessoas não brancas, em especial, os negros.

5. Ver, em Botelho (1998), sobre o Decreto n. 2.368, de 5 de março de 1859, e o Decreto n. 4.154, de 13 de abril de 1868, que tratam da estatística do Império.

6. Criado por José da Silva Paranhos, o Visconde do Rio Branco, o Decreto n. 4.856, de 30 de dezembro de 1871, foi elaborado com base nas experiências extraídas de outros países, nos congressos de estatística e na legislação do censo de 1852 (MACHADO, 2008).

7. Ver, em Botelho (1998) e Machado (2008), a relação entre Igreja e Estado no que diz respeito às estatísticas; os párocos como ponto de apoio para o censo de 1872.

8. A edição original do censo de 1872 foi organizada em 12 volumes, sendo apresentada no ano de 1876 pela Diretoria Geral de Estatística e publicada em forma de relatório, em 1877. Segundo Rodarte e Santos Junior (2008), apenas 50 exemplares da edição original foram disponíveis à venda, transformaram-se em obras raras e se constituíram nas únicas referências aos dados do recenseamento, uma vez que os "boletins de famílias" preenchidos não foram conservados.

9. Essa divulgação de resultados, "afastando-se inteiramente do plano imaginado no começo do serviço, resumiu esta Diretoria em uma só de 446 páginas [...] que seria publicado em mais 7 volumes" (SYNOPSE, 1890, p. ix).

10. Botelho (1998), ao traçar um quadro regionalizado das características da população nas diversas províncias brasileiras, referente ao século XIX, destaca e discute, entre outras coisas, a composição da cor dos habitantes. Mattos (2009) também discute como a definição de cor sofria deslocamentos ao longo do período.

11. De acordo com as instruções para o preenchimento da Lista de Família de 1872, no campo "cor" deveria declarar se "é branca, parda, cabocla ou preta, compreendida na designação cabocla a raça indígena". Segundo o relatório da Diretoria Geral de Estatística (1877, p. 13), na data do recenseamento de 1872, o Brasil era habitado por três raças distintas, a saber: a branca, da qual existem 3.787.289 indivíduos; africana, com 1.954.452; indígena, com 386.955 indivíduos. "Do cruzamento da raça africana com outras resultou a classe dos pardos em número de 3.801.782". No mesmo relatório, o quadro de raças apresenta os itens: branca, negra, indígena e parda. Tal classificação indica que o relator estabelecia uma relação da denominação "negra", com a população preta e africana da época, bem como a indígena com a classificação "cabocla" indicada no censo (p. 14).

12. No que diz respeito à classificação da população segundo as condições sociais, "na época do recenseamento, havia em todo o Império 1.510 .806 escravos, o que resultava em 1 escravo para 5,5 habitantes de condição livre. Na província de Mato Grosso, somava-se 53.750 livres e 6.667 escravos, sendo 1 escravo para 8 pessoas livres (DIRETORIA GERAL DE ESTATÍSTICA, Relatório 1877, p. 8).

13. Nas explicações do censo, o termo "fogo" dá a ideia de domicílio (casa) e "estabelecimento" está ligado à habitação coletiva, tais como comércio, hospital, fazenda, entre outros. Já as palavras "habitação" e "logradouro" são usadas tanto para fogos como para estabelecimentos.

14. Ver Schwarcz (1993), entre outros.

15. O conjunto de instrumentos de coleta de dados do censo de 1890 foi posto por uma ficha de identificação geral do domicílio e três modelos de boletins: o Primeiro Boletim com informações individuais do habitante; o Segundo Boletim, com informações quanto ao indivíduo na família, e o 
Terceiro Boletim, com informações quanto ao indivíduo na sociedade. Esses modelos foram acompanhados de duas explicações: a primeira traz indicações gerais para o preenchimento dos mapas, contendo assim advertências de como proceder ao recenseamento domiciliar e de coletividades; já a segunda apresenta explicações de como preencher os quesitos dos boletins.

16. De acordo com Nadalin (2004), o significado das palavras varia histórica e culturalmente, dependendo da época e do lugar. Ver, também, Gil (2008).

17. Segundo Silva (1995), os dados populacionais da Capitania de Mato Grosso, levantados na segunda metade do século XVIII, estão contidos em treze mapas. A maior parte destes foi elaborada durante os governos de Luiz de Albuquerque e Melo Pereira e Cáceres (1772-1788) e João de Albuquerque de Melo Pereira e Cáceres (1789-1796).

18. No século XIX há vários levantamentos populacionais de Mato Grosso, tais como "Resultados dos trabalhos e indagações estatísticas da província de Mato Grosso (1828-1829)" de Luís d' Alincourt; Mapas da população dos anos de 1815 e 1826, publicados respectivamente pela Revista do Instituto Histórico e Geográfico Brasileiro e Biblioteca Nacional; Censos de 1872 e 1890.

19. No caso do censo de 1872 (p. 46 e 47), afere-se na província de Mato Grosso a população total de 53.750 pessoas livres, sendo 27.991 homens livres (9.027 brancos, 10.827 pardos, 3.861 pretos e 4.278 caboclos) e 25.759 mulheres livres ( 8.210 brancas, 10.087 pardas, 3.214 pretas e 4.248 caboclas). Já os escravos somavam 6.667, sendo 3.632 homens escravos (1.525 pardos e 2.107 pretos) e 3.035 mulheres escravas (1.345 pardas e 1.690 pretas). Segundo o quadro geral da população por sexo, estado civil, nacionalidade, filiação e alfabetização do censo de 1890 (1898, p. 43), a população de Mato Grosso totalizava 92.823 habitantes, sendo 47.193 homens (14.092 brancos, 6.773 pretos, 7.080 caboclos, 19.248 mestiços) e 45.630 mulheres (13.602 brancas, 6.082 pretas, 6.750 cabocla, 19.196 mestiças).

20. Nos mapas populacionais regionais de 1815, 1826 e 1828 os habitantes mato-grossenses foram classificados como brancos, pretos, pardos e índios (D'ALICOURT, 1828; CABRAL, 1857). Nos censos de 1872 e 1890, o termo "caboclo" foi usado para designar os indígenas ou descendentes.

21. Os dados do original do levantamento populacional da província mato-grossense, localizado no Arquivo Público de Mato Grosso, são referendados por Siqueira (2000) e Peraro (1997), entre outros. Atualmente, o documento encontra-se desaparecido do acervo do Arquivo.

22. Para se ter uma noção dessa variação, em 1998, o IBGE incluiu na Pesquisa Mensal de Emprego questões que visaram avaliar como os brasileiros se autoclassificavam em termos de cor. Na pergunta aberta, mais de 130 termos foram utilizados pelos entrevistados para definir sua cor (CARVALHO;WOOD;ANDRADE, 2003).

23. O Decreto n. 4.856, de 30 de dezembro de 1871, estabeleceu que "a respeito das crianças de 6 a 15 anos se notará se frequentam ou não as escolas". Ver, também, a "Lista de Família de 1872".

24. Cf. Censo de 1872 (p. 46 e 47).

25. Ver resultados das pesquisas de Silva (2000), Schuller (2002), Bastos (2007), Fonseca (2002; 2007) e Veiga $(2004 ; 2005)$.

26. Ver o censo de 1872 (p. 46 e 47). Já no que diz respeito aos escravos, o censo apresenta 3.035 mulheres e 3.632 homens analfabetos.

27. De acordo com Faria Filho (2007), o termo "escolarização" pode comportar três sentidos, que não deixam de estar intimamente relacionados.

28. Trabalho fruto da dissertação de mestrado apresenta no Programa de Pós-Graduação da UFMT em 2006. Ver, em Xavier (2007), sobre a sequência graduada dos conteúdos estabelecida pela legislação educacional de Mato Grosso e como os mapas escolares referentes às escolas de meninos e de meninas apresentavam um grau de desenvolvimento maior nas classes da seção de leitura.

29. Titulo do quadro "População recenseada na República dos Estados Unidos do Brasil quanto ao analfabetismo". In: "Sexo, estado civil, nacionalidade, filiação alfabetização da população recenseada em 31 de dezembro de 1890" (1898, p. 373). 
30. Quadro "sexo, estado civil, nacionalidade, filiação alfabetização da população recenseada em 31 de dezembro de 1890 " (1898, p. 373).

\section{Referências}

BARROS, S.A. Negrinhos que por ahi andão: a escolarização da população negra em São Paulo (1870-1920). 2005. Dissertação (estrado em Educação) - Faculdade de Educação, Universidade de São Paulo, São Paulo.

BOTELHO, T.R. População e nação no Brasil do século XIX. 1998. Tese (Doutorado em História Econômica) - Faculdade de Filosofia, Letras e Ciências Humanas, Universidade de São Paulo, São Paulo.

CABRAL, J.A.T. Mappa da população da Capitania de Matto-Gosso em o anno de 1815. Revista do Instituto Histórico e Geográfico Brasileiro, Rio de Janeiro, T. XX, p. 288, 2. Trim. 1857.

CARVALHO, J.A.M.; WOOD, C.H.; ANDRADE, F.C.D. Notas acerca das categorias de cor dos censos e sobre a classificação subjetiva de cor no Brasil: 1980/90. Revista Brasileira de Estudos de População, Campinas, v. 20, n. 1, p. 29-42, 2003.

CARVALHO, J.M. Genocídio racial estatístico. O Globo, Rio de Janeiro, 27 dez. 2004. Disponível em: <http://www.academia.org.br>. Acesso em: 10 ago. 2009. (Sala de Imprensa; Artigos dez. 2004).

FERRARO, A. Analfabetismo e níveis de letramento no Brasil: o que dizem os censos? Educação E Sociedade, Campinas, v. 23, n. 81, p. 21-47, dez. 2002.

FONSECA, M.V. A educação dos negros: uma nova face do processo de abolição da escravidão no Brasil. Bragança Paulista: USF, 2002.

FONSECA, M.V. Pretos, pardos, crioulos e cabras nas escolas mineiras do século XIX. 2007. 250p. Tese (Doutorado) - Faculdade de educação, Universidade de São Paulo, São Paulo.

FOUCAULT, M. A governabilidade. In: FOUCAULT, M. Microfísica do poder. Rio de Janeiro: Graal, 1984. p. 277-293.

GIL, N.L. A dimensão da educação nacional: um estudo sócio-histórico das estatísticas oficiais da escola brasileira. 2007. Tese (Doutorado em Educação) - Faculdade de Educação, Universidade de São Paulo, São Paulo.

HACKING, I. The taming of chance. Cambridge: Cambridge University, 1990.

LAMOUNIER, B. Cor. Disponível em: <http://www.cebrap.org.br/imagens/Arquivos/ cor_bolivar.pdf>. Acesso em: 5 ago. 2009. 
LELLO, J.; LELLO, E. (Dir.). Lello Universal: novo diccionario encyclopédico lusobrasileiro. Porto: Lello, [s.d.]. 4 v.

MACHADO, S.M.C. Os serviços estatísticos em Minas Gerais na produção, classificação e consolidação da instrução pública primária (1871-1931). 2008. Dissertação (Mestrado em Educação) Faculdade de Educação, Universidade de São Paulo, São Paulo.

MARCILIO, M.L. (Org.). Demografia histórica: orientações técnicas e metodológicas. São Paulo: Pioneira, 1977.

MARTIN, O. Da estatística política à sociologia estatística: desenvolvimento e transformação da análise estatística da sociedade (século XVII-XIX). Revista Brasileira de História, São Paulo, v. 21, n. 41, p. 13-34, 2001.

MATTOS, H.M.C. Das cores do silêncio: os significados da liberdade no sudeste escravista - Brasil século XIX. Rio de Janeiro: Arquivo Nacional, 1995.

MATTOS, H.M.C. Racialização e cidadania no Império do Brasil. In: CARVALHO, J.M.; NEVES, L.M.B. (Org.). Repensando o Brasil dos oitocentos. Rio de Janeiro: Civilização brasileira, 2009.

NADALIN, S.O. História e demografia: elemento para um diálogo. Campinas: Associação Brasileira de Estudos Populacionais, 2004.

NÓVOA, A. Prefácio: Governar através dos números. In: CANDEIAS, A. Alfabetização e escola em Portugal nos séculos XIX e XX. Lisboa: Fundação Calouste Gulbenkian, 2004.

OLIVEIRA, J.S. Brasil mostra a sua cara: imagens da população brasileira nos censos demográficos de 1872 a 2000. Rio de Janeiro: IBGE, 2003

PERARO, M.A. Fardas, saias e batina: a ilegitimidade na paróquia Senhor Bom Jesus de Cuiabá, 1853. 1997. Tese (Doutorado) - Universidade Federal do Paraná, Curitiba. PERARO, M.A. A população urbana de Cuiabá em 1890. Cuiabá: UFMT, 2005. (CD-ROM). PESOVENTO, A. Trabalho indígena na província de Mato Grosso (1870-1890). 2004. 118p. Dissertação (Mestrado em História) - Departamento de História, Instituto de Ciências Humanas e Sociais, Universidade de Mato Grosso, Cuiabá.

POPKEWITZ, T.; LINDBLAD, S. Estatísticas educacionais como sistema de razão: relações entre governo da educação e inclusão e exclusão sociais. Educação \& Sociedade, Campinas, v. 22, n. 75, p. 111-148, ago. 2001.

QUETELET, A. A treatise on man and the development of his faculties. Edinburg: William and Robert Charns, 1842. 
RODARTE, M.M.S.; SANTOS JÚNIOR, J.M. A estrutura ocupacional revisitada: uma proposta de correção dos dados do Recenseamento Geral do Império de 1872. In: ENCONTRO NACIONAL DE ESTUDOS POPULACIONAIS, 16., 2008, Caxambú. Anais... Caxambú, Abep, 2008. (CD-ROM). Disponível em: <www.cedeplar.ufmg.br/seminarios/ seminario.../D08A064.pdf> Acesso em: 6 ago. 2009.

SCHUELER, A.F.M. Forma e culturas escolares na cidade do Rio de Janeiro: representações, experiências, e profissionalização docente em escolas públicas primárias. 2002. Tese (Doutorado em Educação) - Universidade Federal Fluminense, Rio de Janeiro.

SCHWARCZ, L.M. O espetáculo das raças: cientistas, instituições e questão racial no Brasil - 1870-1930. São Paulo: Cia das Letras, 1993.

SILVA, A.MP. Aprender com perfeição e sem coação: uma escola para meninos pretos e pardos na Corte. Brasília, DF: Plano, 2000.

SILVA, J.V. Mistura de cores. Cuiabá: UFMT, 1995.

SIQUEIRA, E.M. Luzes e sombras: modernidade e educação pública em Mato Grosso (1870-1889). Cuiabá: Inep; Comped; UFMT, 2000. p. 282.

VEIGA, C.G. Crianças negras e mestiças no processo de institucionalização da instrução elementar, Minas Gerais, século XIX. In: CONGRESSO DA SOCIEDADE BRASILEIRA DE HISTÓRIA DA EDUCAÇÃO, 3., Anais... Curitiba: PUCPR; SBHE. 2004. (CD-ROM).

VEIGA, C.G. A produção da infância nas operações escriturísticas da administração da instrução elementar no século XIX. Revista Brasileira de História da Educação, Campinas, n. 9, p. 73-107, jan./jun. 2005.

VIÑAO FRAGO, A. Alfabetización, lectura y escritura en el Antiguo Régimen (siglos XVI-XVIII). In: ESCOLANO, A. (Dir.). Leer y escribir: doscientos años de alfabetización. Madrid: Fundación Germán Sánchez Ruipérez, 1992. p. 45-68.

XAVIER, A.P.S. A leitura e a escrita na cultura escolar de Mato Grosso (1887-1889). Cuiabá: Entrelinhas; UFMT, 2007.

\section{Documentos}

BIBLIOTECA NACIONAL. Mapa geral da Prelazia de Cuiabá e Mato Grosso, no qual se designam todas as suas Freguesias, e Capelas Filiais com seus respectivos Orgaos, e População: ano de 1826. Rio de Janeiro: Fundação Biblioteca Nacional, 1826. Seção de Manuscritos, I-31,19,16.

BRASIL. Ministério do Interior. Relatório apresentado pelo Ministro de Estado dos Negócios 
do Interior, Dr. João Barbalho Uchoa Calvacanti, ao Presidente da República dos Estados Unidos do Brasil em maio de 1891. Rio de Janeiro: Imprensa Nacional, 1891.

D'ALINCOURT, L. Resultados dos trabalhos e indagações estatísticas da província de Mato Grosso (1828-1829). In: Anais da Biblioteca Nacional. Rio de Janeiro: Fundação Biblioteca Nacional, p. 2; 8; 30.

DIRETORIA GERAL DE ESTATÍSTICA. Boletim de Informações quanto ao Indivíduo na Sociedade. 1890. Disponível em: <http://biblioteca.ibge.gov.br/>. Acesso em: 30 jul. 2009. (Instrumento de coleta, doc. 0915 - pdf).

DIRETORIA GERAL DE ESTATÍSTICA. Boletim Individual. 1900. Disponível em: <http://biblioteca.ibge.gov.br/>. Acesso em: 30 jul. 2009. (Instrumento de coleta, doc. 0916 - pdf).

DIRETORIA GERAL DE ESTATÍSTICA. Decreto n. 659, de 12 de agosto de 1890. In: Instruções para o segundo recenseamento da população da República dos Estados Unidos do Brasil em 31 de dezembro de 1890. Rio de Janeiro: Imprensa Nacional, 1890. p. 2. Disponível em: <http://biblioteca.ibge.gov.br/>. Acesso em: 15 abr. 2009.

DIRETORIA GERAL DE ESTATÍSTICA. Explicações para as pessoas que tiverem que encher os mapas: advertências gerais. In: Instruções para o segundo recenseamento da população da República dos Estados Unidos do Brasil em 31 de dezembro de 1890. Rio de Janeiro: Imprensa Nacional, 1890. p. 23-26. Disponível em: <http://biblioteca.ibge. gov.br/>. Acesso em: 15 abr. 2009.

DIRETORIA GERAL DE ESTATÍSTICA. Explicações quanto ao modo de responder aos quesitos. In: Instruções para o segundo recenseamento da população da República dos Estados Unidos do Brasil em 31 de dezembro de 1890. Rio de Janeiro: Imprensa Nacional, 1890. p. 27-30. Disponível em: <http://biblioteca.ibge.gov.br/>. Acesso em: 15 abr. 2009.

DIRETORIA GERAL DE ESTATÍSTICA. Instruções para o segundo recenseamento da população da República dos Estados Unidos do Brasil a que se refere o Decreto n. 659. In: Instruções para o segundo recenseamento da população da República dos Estados Unidos do Brasil em 31 de dezembro de 1890. Rio de Janeiro, 12 de agosto de 1890. Rio de Janeiro: Imprensa Nacional, 1890. p. 2-11. Disponível em: <http://biblioteca.ibge.gov. br/>. Acesso em: 15 abr. 2009.

DIRETORIA GERAL DE ESTATÍSTICA. Lista de Família. 1872. Disponível em: <http:// biblioteca.ibge.gov.br/>. Acesso em: 30 jul. 2009. (Instrumento de coleta, doc. 1101 pdf).

DIRETORIA GERAL DE ESTATÍSTICA. Recenseamento geral do Império em 1872. Disponível em: <http://biblioteca.ibge.gov.br/>. Acesso em: 30 jul. 2009. 
DIRETORIA GERAL DE ESTATÍSTICA. Relatório e trabalhos estatísticos apresentado pelo Diretor Geral, Conselheiro Manoel Francisco Correia ao Ilm. e Exm. Sr. Conselheiro Dr. José Bento da Cunha e Figueiredo, Ministro e Secretário de Estado dos Negócios do Império, em 31 de dezembro de 1876. Rio de Janeiro: Typographia de Hyppolito José Pinto, 1877. Disponível em: <http://biblioteca.ibge.gov.br/>. Acesso em: 30 jul. 2009.

DIRETORIA GERAL DE ESTATÍSTICA. Relatório apresentado ao Dr. Miguel Calmon du Pin e. Almeida, Ministro da Indústria, Viação e Obras Públicas pelo Dr. José Luiz S. de Bulhões Carvalho, Diretor Geral de Estatística. Rio de Janeiro: Typographia da Estatística, 1908. Disponível em: <http://biblioteca.ibge.gov.br/>. Acesso em: 30 jul. 2009.

DIRETORIA GERAL DE ESTATÍSTICA. Sexo, estado civil, nacionalidade, filiação alfabetização da população recenseada em 31 de dezembro de 1890. Rio de Janeiro: Officina de Estatística, 1898. 442p. Disponível em: <http://biblioteca.ibge.gov.br/>. Acesso em: 30 jul. 2009.

DIRETORIA GERAL DE ESTATÍSTICA. Synopse do Recenseamento de 31 de dezembro de 1890. Rio de Janeiro: Officina da Estatística, 1898. Disponível em: <http://biblioteca. ibge.gov.br/>. Acesso em: 30 jul. 2009.

DIRETORIA GERAL DE ESTATÍSTICA. Synopse do Recenseamento de 31 de dezembro de 1900. Rio de Janeiro: Typographia da Estatística, 1905. Disponível em: <http:// biblioteca.ibge.gov.br/>. Acesso em: 30 jul. 2009.

Recebido em 29 de janeiro de 2011.

Aprovado em 26 de abril de 2012. 